\title{
Research Progress on Nanostructured Radar Absorbing Materials
}

\author{
Yanmin Wang, Tingxi Li, Lifen Zhao, Zuwang Hu, Yijie Gu \\ College of Materials Science and Engineering, Shandong University of Science and Technology, \\ Qingdao Economic \& Technical Development Zone, Qingdao, China \\ E-mail: holylilyee@163.com \\ Received December 14, 2010; revised February 20, 2011; accepted March 7, 2011
}

\begin{abstract}
Nanostructured radar absorbing materials (RAMs) have received steadily growing interest because of their fascinating properties and various applications compared with the bulk or microsized counterparts. The increased surface area, number of dangling bond atoms and unsaturated co-ordination on surface lead to interface polarization, multiple scatter and absorbing more microwave. In this paper, four types of nanostructured RAMs were concisely introduced as follows: nanocrystal RAMs, core-shell nanocomposite RAMs, nanocomposite of MWCNT and inorganic materials RAMs, nanocomposite of nanostructured carbon and polymer RAMs. Their microwave properties were described in detail by taking various materials as examples.
\end{abstract}

Keywords: Nanostructured, Radar Absorbing Materials, Nanocrystal, Nanocomposite

\section{Introduction}

Much attention has been paid to RAMs due to their unique absorbing microwave energy and effectively reducing electromagnetic backscatter so that they are expected to have promising applications in the stealth technology of aircrafts, television image interference of high-rise buildings, and microwave dark-room and protection $[1,2]$. They are specially designed material to suppress the reflected electromagnetic energy incident on the surface of the absorber by dissipating the magnetic and/or electrical fields of the wave into heat. The excellent RAMs should have certain properties as follows: 1) exhibit strong microwave absorption properties over a wide frequency range; 2) need to be thin and lightweight, especially for aircraft; 3) have simple coating-layer structure and spend less working time during the urgent process. Extensive study has been carried out to develop new microwave absorbing materials with a high magnetic and electric loss [3-5]. Nanostructured RAMs have received steadily growing interest because of their fascinating properties such as absorbing more microwave compared with the bulk or microsized counterparts. Nanostructured RAMs mainly consist of the following four types: nanocrystal RAMs, core-shell nanocomposite RAMs, nanocomposite of MWCNT and inorganic materials RAMs, nanocomposite of nanostructured carbon and polymer RAMs.

\section{Nanocrystal RAMs}

The surface area, the number of dangling bond atoms and the unsaturated co-ordination on surface are all increased due to the particle sizes of nanocrystals in the range of nanometer. These lead to interface polarization and multiple scatter, which is useful to absorb more microwave. $\mathrm{La}_{0.8} \mathrm{Ba}_{0.2} \mathrm{MnO}_{3}$ nano-particles (about $80 \mathrm{~nm}$ ) have microwave absorbing properties both in low and high frequency band in range of 2-18 GHz [6]. The value of microwave absorption in low frequency band is larger than that in high frequency. The microwave absorbing peak is $13 \mathrm{~dB}$ at $6.7 \mathrm{GHz}$ and the effective absorbing bandwidth above $10 \mathrm{~dB}$ reaches $1.8 \mathrm{GHz}$ for the sample with the thickness of $2.6 \mathrm{~mm}$. The microwave absorption can be attributed to both the dielectric loss and the magnetic loss from the loss tangents of the sample, but the former is greater than the latter. The morphology and size of the nanocrastals play very important roles in the microwave reflection loss (RL) of the nanocrystals. For the nanocrystal $\mathrm{BaFe}_{12} \mathrm{O}_{19}$ RAMs synthesized under cyclic microwave irradiation [7] from 160 to 760 watts, the degree or extent of the crystallinity of the product increases and the systematic increment in RL appears during irradiation from -4.21 to $-14.45 \mathrm{~dB}$ and -15.20 to 
$-53.69 \mathrm{~dB}$ at minimum and maximum frequencies of $\mathrm{Ku}$ band respectively. Furthermore, the position of minimum RL peak moves towards higher frequency region and the strongest RL of $-53.69 \mathrm{~dB}$ takes place at $14.75 \mathrm{GHz}$ for complete grown nano crystals of pyramidal face.

\section{Core-Shell Nanocomposite RAMs}

To overcome EMI problems, RAMs should have the capability of absorbing unwanted electromagnetic signals so that they should have electric and/or magnetic dipoles which interact with the electromagnetic fields in the radiation. Pure dielectric or magnetic materials are insufficient for absorbing radiation energy. The magnetic-dielectric absorbers of core-shell nanocomposite with suitable dielectric and magnetic properties possess high efficiency because of the complex permittivity and permeability that differ from zero.

The RL of the electroless (Ni-P)/ $\mathrm{BaNi}_{0.4} \mathrm{Ti}_{0.4} \mathrm{Fe}_{11.2} \mathrm{O}_{19}$ nanocomposite powder [8] in $\mathrm{Ku}$ band $(12.4-18 \mathrm{GHz})$ is evidently enhanced to $-28.70 \mathrm{~dB}$, as compared to the electroless Ni-P nanoglobules $(-16.20 \mathrm{~dB})$ and nanocrystalline $\mathrm{BaNi}_{0.4} \mathrm{Ti}_{0.4} \mathrm{Fe}_{11.2} \mathrm{O}_{19}$ powder $(-24.20 \mathrm{~dB})$. After annealing at $400^{\circ} \mathrm{C}$ for $4 \mathrm{~h}$, the $\mathrm{RL}$ and bandwidth of electroless (Ni-P)/ $\mathrm{BaNi}_{0.4} \mathrm{Ti}_{0.4} \mathrm{Fe}_{11.2} \mathrm{O}_{19}$ nanocomposite powder is further improved from -24.20 to $-35.90 \mathrm{~dB}$ and 1.50 to $4.00 \mathrm{GHz}$ respectively. The RL of the annealed (Ni-P)/BaNi ${ }_{0.4} \mathrm{Ti}_{0.4} \mathrm{Fe}_{11.2} \mathrm{O}_{19}$ nanocomposites powder is improved due to the better match between the dielectric loss and magnetic loss because the combination of amorphous electroless Ni-P and $\mathrm{BaNi}_{0.4} \mathrm{Ti}_{0.4} \mathrm{Fe}_{11.2} \mathrm{O}_{19}$ gives the widest bandwidth above $-12 \mathrm{~dB}$ of $4.00 \mathrm{GHz}$. The proposed growth mechanism on the bases of characterization results indicates that the deposition onto the nanoparticulate $\mathrm{BaNi}_{0.4} \mathrm{Ti}_{0.4} \mathrm{Fe}_{11.2} \mathrm{O}_{19}$ powder of electroless Ni-P layer consists of amorphous electroless $\mathrm{Ni}$ matrix, having $\mathrm{Ni}$ and $\mathrm{Ni}_{3} \mathrm{P}$ nanocrystalline particles to form electroless $(\mathrm{Ni}-\mathrm{P}) / \mathrm{BaNi}_{0.4} \mathrm{Ti}_{0.4} \mathrm{Fe}_{11.2} \mathrm{O}_{19}$ nanocomposite powder.

When the $\mathrm{MnFe}_{2} \mathrm{O}_{4}$ is coated with the $\mathrm{TiO}_{2}$ completely, the composites have good compatible dielectric and magnetic properties and hence the microwave absorbing properties show the maximum value. The representative $\mathrm{MnFe}_{2} \mathrm{O}_{4}-\mathrm{TiO}_{2}$ nano-composites [9] exhibit super-para magnetic behavior resulting from $\mathrm{MnFe}_{2} \mathrm{O}_{4}$ nanoparticles and the enhanced imaginary parts of permeability due to the eddy loss of semiconductor $\mathrm{TiO}_{2}$ nanoparticles. The complex permittivity and permeability of $\mathrm{MnFe}_{2} \mathrm{O}_{4}$ and $\mathrm{MnFe}_{2} \mathrm{O}_{4}-\mathrm{TiO}_{2}$ composites measured in the microwave frequency range of $2-10 \mathrm{GHz}$ show that the microwave absorption properties of the $\mathrm{MnFe}_{2} \mathrm{O}_{4}-\mathrm{TiO}_{2}$ composites are higher than that of $\mathrm{MnFe}_{2} \mathrm{O}_{4}$.

Additionally, the $\tan \delta$ of the cupric oxide-nanowire- covered carbon fibers (CNWCFs) shows two peaks when the frequency ranges are $4-13$ and $14-18 \mathrm{GHz}$, respecttively, which indicates wide range microwave absorption in both frequency ranges according to the microwave absorption theory. The absorption frequency and bandwidth of CNWCFs decrease with the thickness increaseing and the optimum thickness of CNWCFs is $1-1.3$ $\mathrm{mm}$ [10]. The reflectivity of CNWCFs (1mmin thickness) is less than $-4 \mathrm{~dB}$ over the range of $11.8-18 \mathrm{GHz}$ and $-10 \mathrm{~dB}$ over the range of $13.5-16 \mathrm{GHz}$, while the reflectivity of CNWCFs (1.3mm in thickness) is less than $-4 \mathrm{~dB}$ over the range of $8.6-15 \mathrm{GHz}$ and $-10 \mathrm{~dB}$ over the range of $9.8-13 \mathrm{GHz}$.

\section{Nanocomposite of MWCNT and Inorganic Materials RAMs}

Although $\varepsilon_{r}{ }^{\prime \prime}$ of the purified MWCNTs is larger than 40 between 2 and $18 \mathrm{GHz}$ and even exceeds 100 at lower frequencies, the RL still remains rather small, because another important parameter relating to $\mathrm{RL}$ is the concept of matched characteristic impedance, where the characteristic impedance of the absorbing material should be made nearly equal to that of the free space $\left(377 \Omega \cdot \mathrm{sq}^{-1}\right)$ to achieve zero-reflection at the front surface of the material [11]. Nanocomposite of MWCNT and inorganic materials could be good candidate because the combination of both materials brings about better matched characteristic impedance and improved RL.

Although the RL of purified MWCNTs keeps constantly at $1 \mathrm{~dB}$ except for a small peak of $1.23 \mathrm{~dB}$ at 2.8 $\mathrm{GHz}$, the RL of MWCNT filled and surface decorated with $\gamma-\mathrm{Fe}_{2} \mathrm{O}_{3}$ is larger than $3 \mathrm{~dB}$ between 5 and $18 \mathrm{GHz}$ with a maximum of $5.32 \mathrm{~dB}$ at $7.0 \mathrm{GHz}$. When $\gamma-\mathrm{Fe}_{2} \mathrm{O}_{3}$ is transformed to $\mathrm{Fe} / \mathrm{Fe}_{3} \mathrm{C}$ by heat-treatment in $\mathrm{H}_{2}$ atmosphere at $950^{\circ} \mathrm{C}$ [12], the microwave absorption of the $\mathrm{Fe} / \mathrm{Fe}_{3} \mathrm{C}-\mathrm{MWCNT}$ composite is enhanced greatly at all frequencies between 2 and $18 \mathrm{GHz}$ so that the RL is larger than $3 \mathrm{~dB}$ between 4.6 and $18 \mathrm{GHz}$ with a maximum of $12.57 \mathrm{~dB}$ locating at $9.2 \mathrm{GHz}$. This result from enhanced magnetic loss and better matched characteristic impedance, rather than electric loss, as shown by the complex relative permeability and permittivity. The frequency corresponding to the maximum $\mathrm{RL}$ of $\mathrm{Fe} / \mathrm{Fe}_{3} \mathrm{C}-$ MWCNT composite shows an inverse relationship with the increase in its thickness and the maximum attenuation of the incident wave is increased from 11.00 (12.40 $\mathrm{GHz})$ to $13.88(4.60 \mathrm{GHz})$ when the thickness is increased from 1.5 to $3.5 \mathrm{~mm}$. The microwave absorbing properties can be modulated simply by manipulating the thickness of the prepared $\mathrm{Fe} / \mathrm{Fe}_{3} \mathrm{C}-\mathrm{MWCNT}$ composite for application in different frequency bands.

The $\mathrm{Er}_{2} \mathrm{O}_{3}$ nanoparticles encapsulated in the cavities of 
MWCNTs could also modulate the electromagnetic parameters of MWCNTs, and thus affect the microwave absorbing properties. The $\mathrm{Er}_{2} \mathrm{O}_{3}$-filled MWCNTs possess much broader absorbing bandwidth and larger reflectiveity, complex permeability and magnetic loss tangent than unfilled MWCNTs [13]. The maximum absorbing peak of raw MWCNTs is about $-21.58 \mathrm{~dB}$ at $9.4 \mathrm{GHz}$ in the range of $X$ wave band with the thickness $(\mathrm{dm})$ of $2.0 \mathrm{~mm}$, the bandwidth of the reflectivity below $-5 \mathrm{~dB}$ is 3.50 $\mathrm{GHz}$ and the bandwidth of the reflectivity below $-10 \mathrm{~dB}$ is $1.58 \mathrm{GHz}$. In contrast, under the same matching thickness $(\mathrm{dm}=2.0 \mathrm{~mm})$, the maximum absorbing peak of the $\mathrm{Er}_{2} \mathrm{O}_{3}$-filled MWCNTs increases to $-27.96 \mathrm{~dB}$ and shifts to $10.0 \mathrm{GHz}$, the bandwidth of the reflectivity below -5 $\mathrm{dB}$ is $4.65 \mathrm{GHz}$ and the bandwidth of the reflectivity below $-10 \mathrm{~dB}$ is $2.30 \mathrm{GHz}$. With the increase of thickness, the peak value of reflectivity shifts to lower frequencies and multiple absorbing peaks appear.

There are three reasons for the improved absorbing performance of $\mathrm{Er}_{2} \mathrm{O}_{3}$ modified MWCNTs as follows: firstly, the specific location of the Er ion in MWCNTs could generate a charge effect [14] and RE oxide located in MWCNTs cavities could change the microenvironment of the resonators MWCNTs; secondly, the energy levels of the nanosized $\mathrm{Er}_{2} \mathrm{O}_{3}$ crystals encapsulated in one-dimensional MWCNTs are not continuous but discrete because of quantum confinement effect according to Kubo theory; finally, the $\mathrm{Er}^{3+}$ ion has the [Xe] $4 \mathrm{f}$ configuration, the $5 \mathrm{~d}$ shell is empty and there are three unpaired $4 \mathrm{f}$ electrons interacting with the crystalline environment. The electron magnetic moment may cause a large magnetic loss in the composite.

\section{Nanocomposite of Nanostructured Carbon and Polymer RAMs}

Carbon nanotubes (CNTs) as conductive filler have been widely studied in RAMs due to their physical and chemical properties such as light weight and strong microwave absorption properties in the $\mathrm{GHz}$ frequency range [15]. For CNTs/polymer (PET, PP, PE and varnish) nanocomposites [16], the position of reflectivity peak moves to a lower frequency and the loss factors of composites increase with increasing CNTs concentrations. At the CNTs concentration of above $4 \mathrm{wt} \%$, loss tangent of the composites sharply increases because this behavior corresponds to a phase transition from an insulator to a conducting composite at this concentration and a drastic change in the electrical resistivity with a corresponding change in the behavior of its electromagnetic characteristics. Polymer matrix has an obvious effect on microwave absorbing properties. CNTs/PET composite achieves a maximum absorbing value of $17.61 \mathrm{~dB}$ and RL of over 5
$\mathrm{dB}$ between $5 \mathrm{GHz}$ and $18 \mathrm{GHz}$, while the maximum absorbing value of CNTs/varnish composite is $24.27 \mathrm{~dB}$. However, CNTs/PE composite has a maximum absorbing value of $8.01 \mathrm{~dB}$ when CNTs concentration is up to 8 $\mathrm{wt} \%$. In addition, the frequencies range for absorbing values exceeding $5 \mathrm{~dB}$ of $\mathrm{CNTs} /(\mathrm{PET}, \mathrm{PP}$, varnish) composites are $13 \mathrm{GHz}, 10 \mathrm{GHz}$ and $6 \mathrm{GHz}$, respectively. The microwave absorption of CNTs composites can be mainly attributed to the dielectric loss rather than magnetic loss because the value of dielectric loss is much higher than that of magnetic loss especially in frequentcies ranging from $6 \mathrm{GHz}$ to $18 \mathrm{GHz}$.

Compared to the raw GFR (Glass Fiber-Reinforced) composites (G8, G16) with low absorbing efficiency, the GFR nanocomposites consisting of glass fiber, epoxy and nanosized carbon materials such as $\mathrm{CB}$ (carbon black) 16, MWCNT8 and MWCNT16 show outstanding absorbing efficiency over $10 \mathrm{~dB}$ between 8 and $12 \mathrm{GHz}$ frequency range (as shown in Figure 1). Especially, the GFR-MWCNT composite with 16 plies (MWCNT16) provides three times higher efficiency than those of $\mathrm{CB}$ composites (CB16) [17].

When the onion-like carbon (OLC) is dispersed in different polymer matrix such as PMMA and epoxy [18], the EM reflection provided by OLC is higher when embedded into PMMA host matrix because the higher adhesion of PMMA and OLC agglomerates provide formation of more homogeneous distribution of OLC within polymer matrix. OLC content essentially influences the EM absorption for OLC/PMMA films: the EM attenuation increases as much as 2.5 times with the increasing of OLC concentration from 2 to $20 \mathrm{wt} \%$ for whole frequency range. More efficient shielding properties have been observed for OLC aggregates of the smallest sizes as compared to larger-sized aggregates at the same OLC loading, as is attributed to the better dispersion and formation of a continuous conductive network by smaller aggregates (reaching the significantly lower percolation threshold) [19].

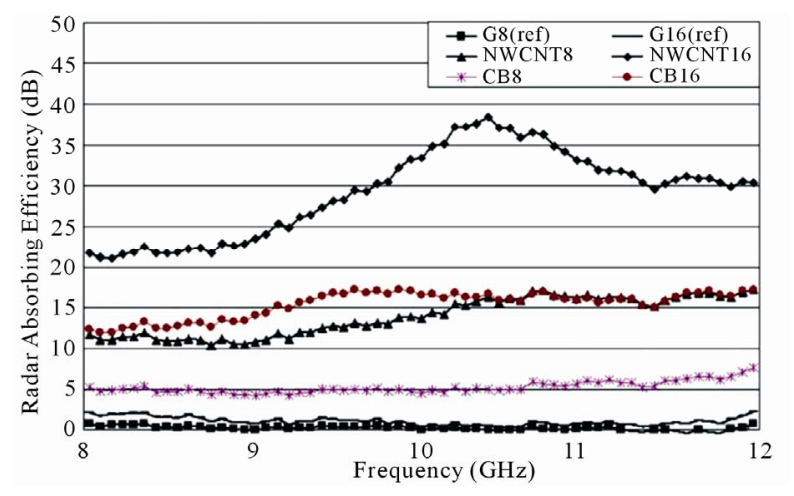

Figure 1. Comparison of radar absorbing efficiency for raw GFR and GFR nanocomposite. 
For E-glass/epoxy composite laminates containing three different types of carbon nano materials such as carbon black (CB), carbon nanofiber (CNF) and multiwall carbon nanotube (MWNT) [20], the real and imaginary parts of the complex permittivities of the composites are proportional to the filler concentrations. Depending on the types of fillers and frequency band, the increasing rates of the real and imaginary parts with respect to the filler concentrations are all different with the order of $\mathrm{CNF}>\mathrm{MWNT}$ » $\mathrm{CB}$. These different rates can have great effect on the thickness in designing the single-layer microwave absorbers and the order of thickness of composite materials at their optimums is $\mathrm{CNF}<$ MWNT «CB. The excellence of CNF originates from its high conductivity and straightness offering the possibility of big electric dipoles and inducing higher dielectric constant of composites.

The mixed type absorbers employing two fillers for both dielectric and magnetic characteristics are possible candidate materials for overcoming the narrow absorption of dielectric RAMs and heavy weight of magnetic RAMs. The mixed RAMs containing carbon nanofibers (CNFs) as dielectric lossy materials to increase permittivity and $\mathrm{NiFe}$ particles as magnetic lossy materials [21] show improved absorbing characteristics with thinner matching thicknesses. The present mixed RAMs show the $10 \mathrm{~dB}$ absorbing bandwidth of $4.0 \mathrm{GHz}$ in the X-band (2.00 mm thickness) and $6.0 \mathrm{GHz}$ in the Ku-band (1.49 mm thickness).

\section{Conclusions}

Nanostructured RAMs possess enhanced absorbing property due to the nanometer size. The morphology and size of the nanocrastal RAMs play very important roles in the microwave RL of the nanocrystals and, as the degree or extent of the crystallinity increases, the systematic increment in RL appears. The magnetic-dielectric absorbers of core-shell nanocomposite RAMs with suitable dielectric and magnetic properties possess high efficiency because of the complex permittivity and permeability that differ from zero. Nanocomposite of MWCNT and inorganic materials RAMs combines better matched characteristic impedance and improved reflection loss of both materials. For nanocomposite of CNTs and polymer RAMs, the position of reflectivity peak moves to a lower frequency and the loss factors of composites increase with increasing CNTs concentrations. More efficient shielding properties had been observed for OLC aggregates of the smallest sizes as compared to larger-sized aggregates at the same OLC loading. The increasing rates of the real and imaginary parts for nanocomposite of nanostuctured carbon and polymer RAMs with respect to the filler concentrations depend on the types of fillers and frequency band.

\section{Acknowledgements}

The authors wish to thank SRF for ROCS, SEM for financial support for this work.

\section{References}

[1] J. Y. Shin and J. H. Oh, "The Microwave Absorbing Phenomena of Ferrite Microwave Absorbers," IEEE Transactions on Magnetics, Vol. 29, No. 6, 1993, pp. $3437-$ 3439. doi: $10.1109 / 20.281188$

[2] C.-H. Peng, C.-C. Hwang, J. Wan, J.-S. Tsai and S.-Y. Chen, "Microwave-Absorbing Characteristics for the Composites of Thermal-Plastic Polyurethane (TPU)-bonded NiZn-Ferrites Prepared by Combustion Synthesis Method," Materials Science and Engineering: B, Vol. 117, No. 1, 2005, pp. 27-36. doi:10.1016/j.mseb.2004.10.022

[3] S. Ruan, B. Xu, H. Suo, F. Wu, S. Xiang and M. Zhao, "Microwave Absorptive Behavior of ZnCo-Substituted W-type Ba Hexaferrite Nanocrystalline Composite Material," Journal of Magnetism and Magnetic Materials, Vol. 212, No. 1-2, 2000, pp. 175-177. doi:10.1016/S0304-8853(99)00755-6

[4] V. K. Babbar, A. Razdan, R. A. Puri and T. C. Goel, "Complex Permittivity, Permeability, and X-band Microwave Absorption of CaCoTi Ferrite Composites," Journal of Applied Physics, Vol. 87, No. 9, 2000, pp. 4362 4366. doi:10.1063/1.373079

[5] S. B. Cho, D. H. Kang and J. H. Oh, "Relationship between Magnetic Properties and Microwave-absorbing Characteristics of NiZnCo Ferrite Composites," Journal of Materials Science, Vol. 31, No. 17, pp. 4719-4722. doi:10.1007/BF00366375

[6] K. Zhou, J. Deng, L. Yin, S. Ma and S. Gao, "Microwave Absorbing Properties of $\mathrm{La}_{0.8} \mathrm{Ba}_{0.2} \mathrm{MnO}_{3}$ Nano-Particles," Transactions of Nonferrous Metals Society of China, Vol. 17, No. 5, 2007, pp. 947-950. doi:10.1016/S1003-6326(07)60205-2

[7] R. Sharma, R. C. Agarwala and V. Agarwala, "Development of Radar Absorbing Nano Crystals by Microwave Irradiation," Materials Letters, Vol. 62, No. 15, 2005, pp. 2233-2236. doi:10.1016/j.matlet.2007.11.076

[8] R. Sharma, R. C. Agarwala and V. Agarwala, "Development of Electroless (Ni-P)/ $\mathrm{BaNi}_{0.4} \mathrm{Ti}_{0.4} \mathrm{Fe}_{11.2} \mathrm{O}_{19}$ Nanocompo- site Powder for Enhanced Microwave Absorption," Journal of Alloys and Compounds, Vol. 467, No. 1-2, 2009, pp. 357-365. doi:10.1016/j.jallcom.2007.11.141

[9] H.-M. Xiao, X.-M. Liu and S.-Y. Fu, "Synthesis, Magnetic and Microwave Absorbing Properties of Core-shell Structured $\mathrm{MnFe}_{2} \mathrm{O}_{4} / \mathrm{TiO}_{2}$ Nanocomposites," Composites Science and Technology, Vol. 66, No. 13, 2006, pp. 2003 -2008. doi:10.1016/j.compscitech.2006.01.001

[10] J. Zeng, P. Tao, S. Wang and J. Xu, "Preparation and Study on Radar-Absorbing Materials of Cupric Oxide- 
nanowire-Covered Carbon Fibers," Applied Surface Science, Vol. 255, No.9, 2009, pp. 4916-4920. doi:10.1016/i.apsusc.2008.12.036

[11] K. J. Vinoy and R. M. Jha, "Radar Absorbing Materials: From Theory to Design and Characterization," Kluwer Academic Publishers, Boston, 1996. doi:10.1007/978-1-4613-0473-9

[12] P. Xu, X. J. Han, X. R. Liu, B. Zhang, C. Wang and X. H. Wang, "A Study of the Magnetic and Electromagnetic Properties of $\gamma-\mathrm{Fe}_{2} \mathrm{O}_{3}-$ Multiwalled Carbon Nanotubes (MWCNT) and $\mathrm{Fe} / \mathrm{Fe}_{3} \mathrm{C}-\mathrm{MWCNT}$ Composites," Materials Chemistry and Physics, Vol. 114, No. 2-3, 2009, pp. 556-560. doi.10.1016/j.matchemphys.2008.10.010

[13] L. Zhang, H. Zhu, Y. Song, Y. Zhang and Y. Huang, "The Electromagnetic Characteristics and Absorbing Properties of Multi-walled Carbon Nanotubes Filled with $\mathrm{Er}_{2} \mathrm{O}_{3}$ Nanoparticles as Microwave Absorbers," Materials Science and Engineering: B, Vol. 153, No. 1-3, 2008, pp. 78-82. doi:10.1016/j.mseb.2008.10.029

[14] H. J. Wang, D. H. Yu, P. Sun, J. Yan, Y. Wang and H. Huang, "Rare Earth Metal Modified NaY: Structure and Catalytic Performance for Lactic Acid Dehydration to Acrylic Acid," Catalysis Communications, Vol. 9, No. 9, 2008, pp. 1799-1803. doi:10.1016/j.catcom.2008.01.023

[15] R. C. Che, L. M. Peng, X. F. Duan, Q. Chen and X. L. Liang, "Microwave Absorption Enhancement and Complex Permittivity and Permeability of Fe Encapsulated within Carbon Nanotubes," Advanced Materials, Vol. 16, No. 5, 2004, pp. 401-405. doi:10.1002/adma.200306460

[16] Z. Fan, G. Luo, Z. Zhang, L. Zhou and F. Wei, "Electromagnetic and Microwave Absorbing Properties of Multi-
Walled Carbon Nanotubes/Polymer Composites," Materials Science and Engineering: B, Vol. 132, No. 1-2, 2006, pp. 85-89. doi:10.1016/j.mseb.2006.02.045

[17] W.-K. Jung, B. Kim, M.-S. Won and S.-H. Ahn, "Fabrication of Radar Absorbing Structure (RAS) Using GFR-nano Composite and Spring-back Compensation of Hybrid Composite RAS Shells," Composite Structures, Vol. 75, No. 1-4, 2006, pp. 571-576. doi:10.1016/j.compstruct.2006.04.077

[18] P. Kuzhir, S. Maksimenko, D. Bychanok, V. Kuznetsov, S. Moseenkov and I. Mazov, et al., "Nano-Scaled Onionlike Carbon: Prospective Material for Microwave Coatings," Metamaterials, Vol. 3, No. 3-4, 2009, pp. 148-156. doi:10.1016/j.metmat.2009.07.002

[19] N. N. Gavrilov, A. V. Okotrub, L. G. Bulusheva, V. L. Kuznetsov and S. I. Moseenkov, "Low-Frequency (10-50 $\mathrm{kHz}$ ) Impedance of Polystyrene-Onion-Like-Carbon Composites," Technical Physics Letters, Vol. 37, No. 1, 2009, pp. 85-88. doi:10.1134/S106378500901026X

[20] J.-B. Kim, S.-K. Lee and C.-G. Kim, "Comparison Study on the Effect of Carbon Nano Materials for Single-Layer Microwave Absorbers in X-Band," Composites Science and Technology, Vol. 68, No. 14, 2008, pp. 2909-2916. doi:10.1016/j.compscitech.2007.10.035

[21] K.-Y. Park, J.-H. Han, S.-B. Lee, J.-B. Kim, J.-W. Yi and S.-K. Lee, "Fabrication and Electromagnetic Characteristics of Microwave Absorbers Containing Carbon Nanofibers and NiFe Particles," Composites Science and Technology, Vol. 69, No. 7-8, 2009, pp. 1271-1278. doi:10.1016/j.compscitech.2009.02.033 